\title{
Pemetaan gua janjian untuk konservasi karst di talago gunung, sawahlunto
}

\author{
Riko Maiyudi $^{1)^{*}}$, Harizona Aulia Rahman ${ }^{2)}$, Fadel Muhammad ${ }^{3)}$ \\ ${ }^{123}$ Fakultas Teknik, Jurusan Teknik Pertambangan,Universitas Negeri Padang, Indonesia \\ rikomaiyudi@ft.unp.ac.id *; harizonarahman@ft.unp.ac.id ; 011fadelmuhammad@gmail.com
}

\begin{abstract}
ABSTRAK
Kota Sawahlunto memiliki banyak potensi bentang alam karst. Salah satunya adalah Gua Janjian yang terletak di Desa Talago Gunung, Kecamatan Barangin. Pemetaan adalah tahap pertama untuk melihat kondisi gua dan identifikasi objek di dalam gua. Pemetaan pengukuran menggunakan alat bantu seperti kompas, klinometer, pita ukur dan distometer. Metode yang digunakan dalam pemetaan ini adalah metode offset. Pengukuran menggunakan satu titik referensi atau stasiun dari pengamatan GPS. Dari data sudut horizontal, sudut vertikal, dan informasi jarak dapat diperoleh nilai posisi $\mathrm{x}$, y dan $\mathrm{z}$ titik pengamatan yang diambil dari referensi stasiun. Penampang goa dilakukan dengan mengukur jarak ke kiri dan kanan goa, atap dan lantai goa pada titik stasiun pengamatan. Hasil pemetaan ini adalah peta Gua Janjian dan sebaran speleotema. Dari penelitian ini diharapkan dapat menjadi tahap awal konservasi karst di Gua Janjian.
\end{abstract}

Kata kunci: Sawahlunto, Gua Janjian, Konservasi

\section{ABSTRACT}

Sawahlunto city has many potential karst landscapes. One of them are Janjian Cave located in the village of Talago Gunung, Barangin District. Mapping is the first stage to see the cave's conditions and identification object in the cave. Mapping measurement using tools such as a compass, clinometer, measuring tape and distometer. The method used in this mapping is the offset method. Measurements using one reference point or station from GPS observations. From the horizontal angle data, vertical angle, and distance information, it can be obtained the value of the $x, y$ and $z$ position of the observation points taken from station reference. The cross section of the cave is carried out by measuring the distance to the left and right cave, roof and floor of cave at the observation station points. The results of this mapping are Janjian Cave map and speleothems distribution. From this research, it's hoped that it will become first stage for karst conservation in Janjian.

Keywords: Sawahlunto, Janjian Cave, Mapping, Conservation

diunggah: November 2021, direvisi: Desember 2021, diterima: Desember 2021, dipublikasi: Desember 2021 Copyright (c) 2021 Riko Maiyudi, Harizona Aulia Rahman, Fadel Muhammad This is an open access article under the CC-BY license

\section{PENDAHULUAN}

Indonesia merupakan negara yang memiliki banyak pegunungan kapur, seluas 15,4 juta hektar (Agniy, 2019). Salah satunya di Kota Sawahlunto.Karst merupakan karakteristik hidrologis dan bentuklahan yang disebabkan oleh kombinasi batuan terlarut dan porositas sekunder yang berkembang dengan baik (Alt, 2013). Karst berkembang pada batuan terlarut seperti batugamping, dolomit, dan batuan asin pada kondisi iklim yang mendukung proses pelarutan.

Peraturan-peraturan pengelolaan lingkungan hidup khususnya perlindungan kawasan karst mengacu (Pasal 4 UU No.32 Tahun 2009), yang dapat dijadikan poin penting untuk mengkaji 
lebih dalam upaya perlindungan hukum di kawasan karst (Ford, 2013). Pemetaan adalah upaya untuk menyampaikan, menganalisis, dan mengklasifikasikan data yang bersangkutan, serta dengan mudah menyampaikannya ke dalam peta, memberikan gambaran yang jelas, rapi, dan bersih.

Pemetaan gua merupakan upaya pendokumentasian gua, sehingga peta tersebut menjadi informasi bagi gua lainnya. Peta tersebut memberikan deskripsi gua, ukurannya, ornamen yang menghiasinya. Peta dapat menjadi alat atau sumber informasi sebelum memasuki guagua tertentu. Pemetaan juga memberikan informasi ilmiah yang berguna untuk penelitian ilmiah. Peta gua juga berarti bukti bahwa seorang penjelajah gua telah memasuki atau menjelajahi gua (Matius, 2016). Pemetaan gua juga dapat digunakan untuk mengidentifikasi objek di dalam gua. Pemetaan gua, serta karakterisasi rongga atau sungai bawah tanah, sangat penting dalam mendukung pengambilan keputusan dalam pengelolaan kawasan karst (Nurkholis, 2017). Sehingga keberadaan benda-benda tersebut diketahui melalui peta.

Pemetaan dan analisis dampak lingkungan dapat digunakan untuk mendukung keputusan pengelolaan di gua konservasi, seperti perencanaan infrastruktur dan upaya pemantauan (Sarwanto, 2015). Penelitian ini bertujuan untuk memetakan kawasan karst di Gua Janjian, Sawahlunto. Ini merupakan tahap awal untuk melindungi potensi sumber daya alam dan non hayati. Dengan demikian, langkah-langkah yang dilakukan dapat menjadi tahapan konservasi karst di goa janjian.

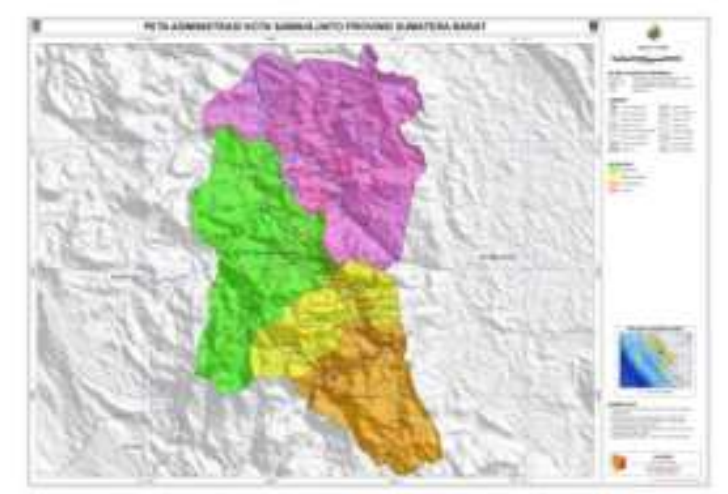

\section{Gambar 1. Peta administrasi sawahlunto}

\section{METODE PENELITIAN}

\section{Area penelitian}

Daerah penelitian dilakukan di kawasan karst Kota Sawahlunto yang secara geografis terletak pada koordinat 100o 44' 22,93" Bujur Timur dan 0o 40' 15,3". Daerah penelitian di Sawahlunto ditunjukkan pada gambar 2.

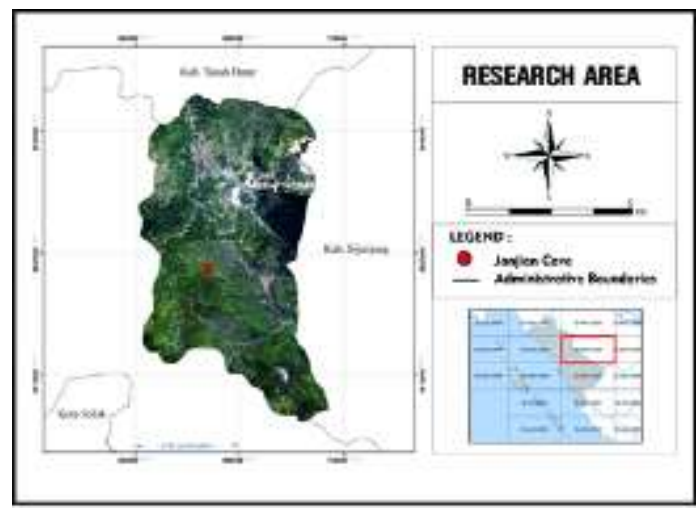

Gambar 2. Daerah penelitian 


\section{Fase penelitian}

Penelitian ini menggunakan 3 fase yaitu:

1. Tahap Persiapan

a. Studi literatur mengenai daerah penelitian terkait dengan kondisi bentuk gua dan metode pemetaan yang sesuai digunakan dalam pengukuran gua. Kondisi daerah penelitian meliputi iklim, bentang alam dan lingkungan sekitarnya.

b. Survei pengintaian yang dilakukan pada awal penelitian bertujuan untuk memperoleh data awal sebagai bagian penting dari bahan kajian teknis dan bahan untuk penelitian selanjutnya.

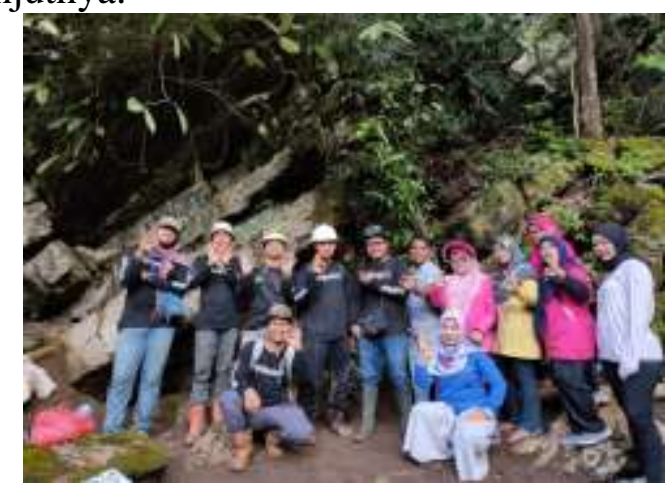

Gambar 3. Persiapan penelitian

2. Pengumpulan Data Lapangan

a. Pengambilan titik ikat digunakan sebagai acuan dalam melakukan pengukuran dan diketahui ketinggiannya serta sudah memiliki koordinat.

b. Pengumpulan data lengkap jarak, sudut dan lebar gua dilakukan untuk mendapatkan informasi yang diperlukan untuk mencapai tujuan penelitian.

c. Pendataan ragam hias digunakan untuk mengetahui tata letak ragam hias di dalam goa terhadap peta yang dibuat.

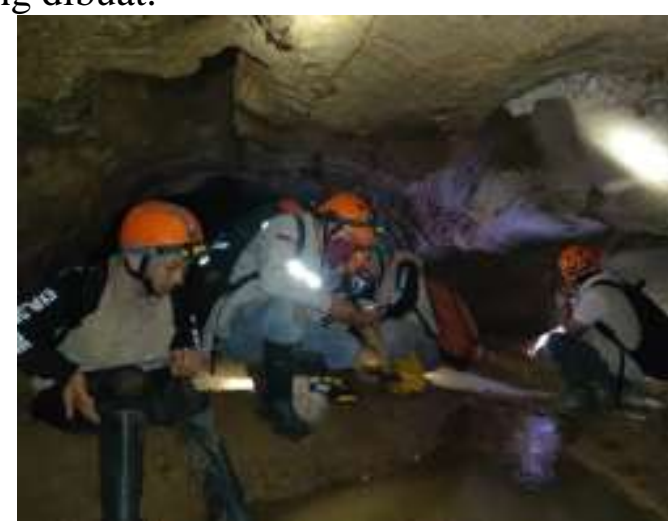

Gambar 4. Pengumpulan data lapangan

3. Mengolah data

Pengolahan data dalam penelitian ini adalah mencari nilai jarak horizontal (HD), jarak vertikal (, absis (x), biasa (y) dan elevasi (h) (Sarwanto, 2015). Rumus yang digunakan adalah sebagai berikut $(V D)$ :

Perbedaan tinggi (jarak vertikal) gunakan rumus :

$$
(V D)=\mathrm{SD} \times \sin \Theta v(2)
$$

Di mana ( perbedaan tinggi $\triangle h$ ), SD adalah jarak kemiringan dan sudut vertikal dari klinometer $\Theta v$ 
Horizontal Distance (HD) menggunakan rumus:

$$
\mathrm{HD}=\mathrm{SD} \times \cos \Theta \mathrm{h}(5)
$$

Sumbu X menggunakan rumus :

$$
\mathrm{Xn}=\mathrm{Xn}-1+\mathrm{HD} \mathrm{X} \sin \mathrm{Az}(6)
$$

Di mana $X n$ adalah $X$ pengamatan,Xn-1 adalah pengamatan titik $X$ sebelumnya, Az adalah sudut azimuth dari kompas

Sumbu Y menggunakan rumus :

$$
\mathrm{Yn}=\mathrm{Yn}-1+\mathrm{HD} \cos \mathrm{Az}(9)
$$

Di mana Yn adalah pengamatan Y,Yn-1 adalah pengamatan titik Y sebelumnya.

Ketinggian (h) gunakan rumus :

$$
\mathrm{hn}=\mathrm{hn}-1+\mathrm{VD}(8)
$$

Di mana hn adalah $\mathrm{h}$ pengamatan,hn-1 adalah pengamatan titik $\mathrm{h}$ sebelumnya, VD adalah jarak vertikal

\section{HASIL DAN PEMBAHASAN}

Hasil dari penelitian ini adalah peta Gua Janjian full segment dan per segment. Gambar 5. menunjukkan segmen penuh untuk peta Gua Janjian.

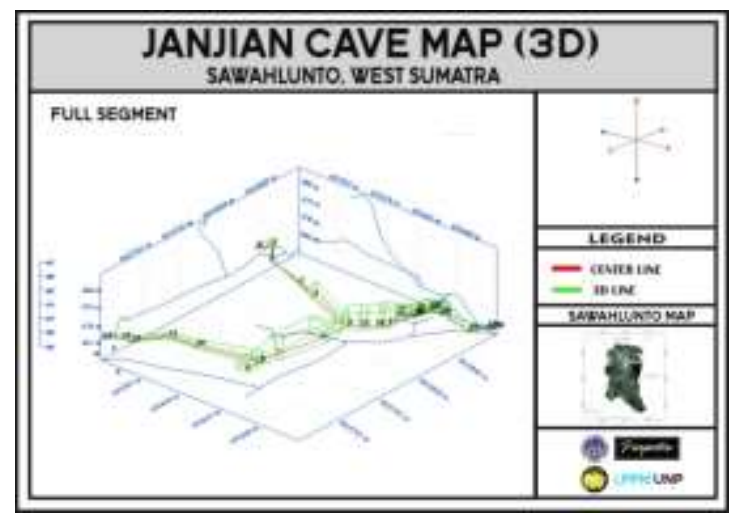

Gambar 5. Peta 3D gua janjian (full segment)

Penelitian ini membagi daerah penelitian menjadi 6 segmen, gambar 6. menunjukkan segmen 1 untuk peta Gua Janjian. 


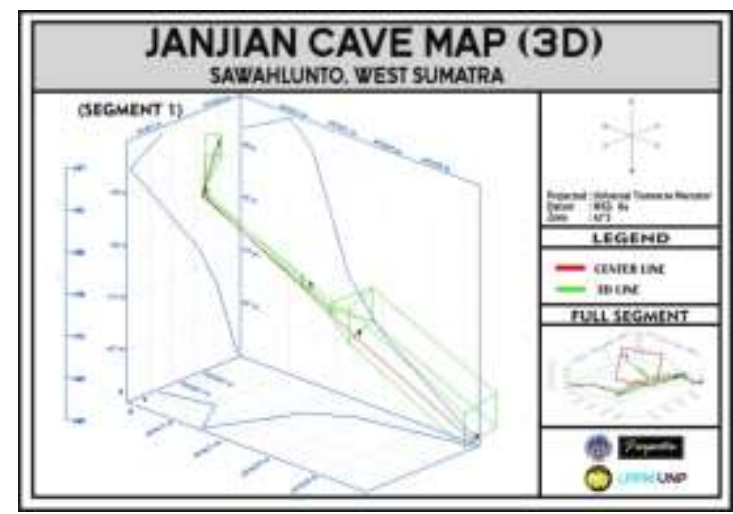

Gambar 6. Peta gua janjian segmen 1

Segmen 1 menunjukkan pintu masuk gua, dan lebar gua menyempit di tengah segmen 1. Diperlukan kehati-hatian saat melewati segmen 1. Setelah melewati segmen 1 akan menemui percabangan gua. Terdapat 2 segmen di cabang kanan segmen 1, dan 3 segmen di segmen cabang kiri 1. Gambar 7. menunjukkan segmen 2 untuk peta Gua Janjian.

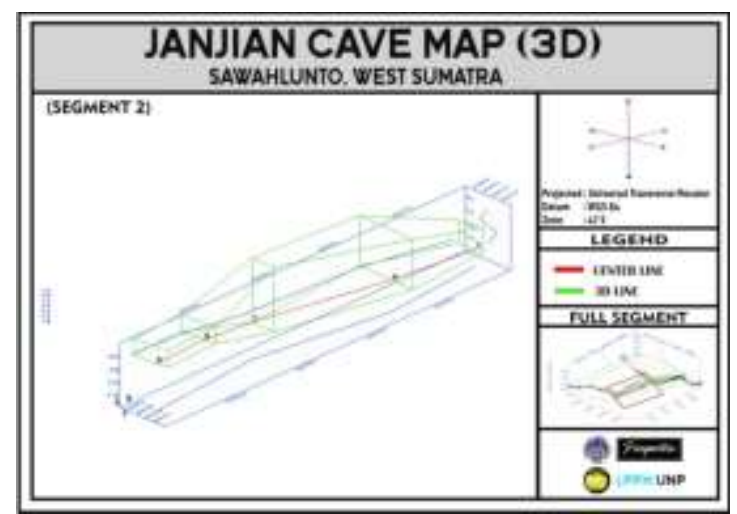

Gambar 7. Peta gua janjian segmen 2

Segmen 2 dan segmen 3 merupakan cabang kanan dari segmen 1 yang area dalamnya cukup luas dan tinggi.Gambar 8. menunjukkan segmen 3 untuk peta Gua Janjian.

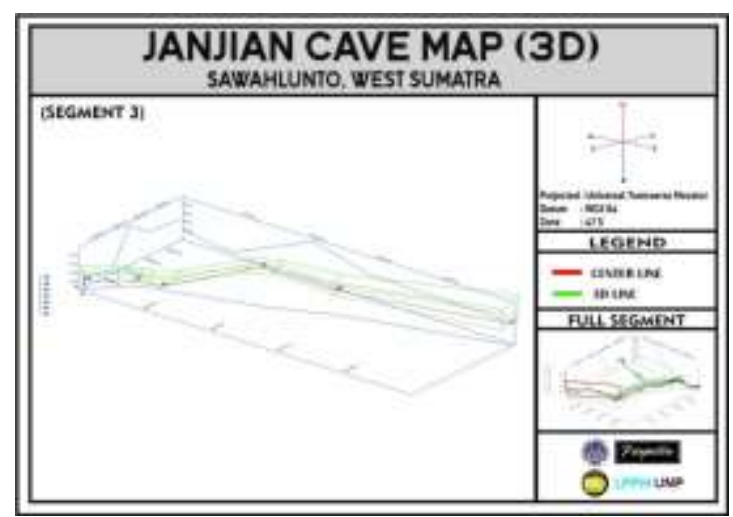

Gambar 8. Peta gua janjian segmen 3

Segmen 4, 5 dan 6 merupakan percabangan kiri segmen 1 yang area dalamnya cukup luas dan tinggi. Gambar 9. menunjukkan segmen 4 untuk peta Gua Janjian. 


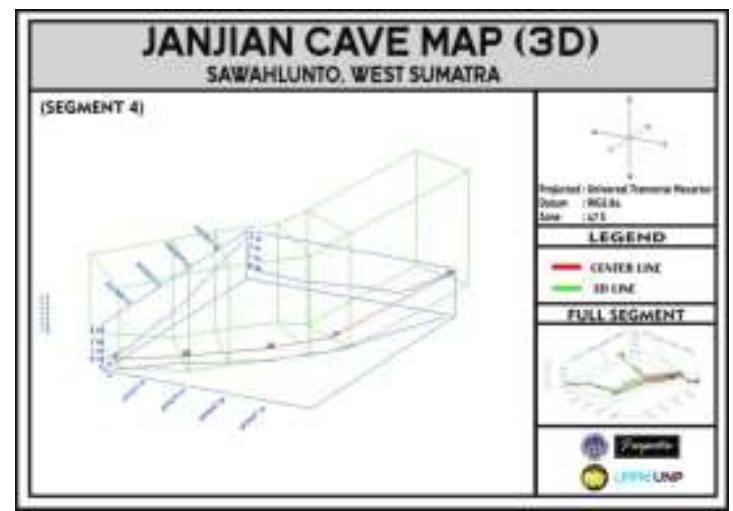

Gambar 9. Peta gua janjian segmen 4

Segmen 5 memiliki area yang terjal, terlihat dari penurunan segmen 5. Gambar 10. menunjukkan segmen 5 untuk peta Gua Janjian.

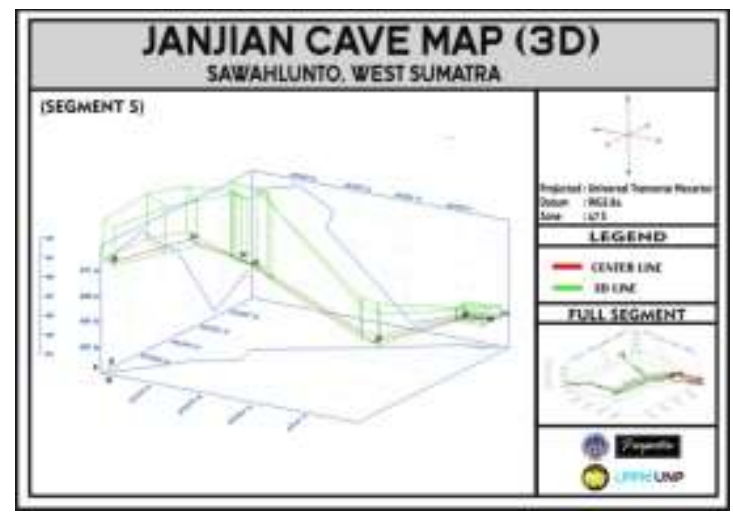

Gambar 10. Peta gua janjian segmen 5

Segmen 6 terdapat 3 cabang yang tidak dapat dijangkau karena rawan longsor dan area yang sempit Gambar 11. menunjukkan segmen 6 untuk peta Gua Janjian.

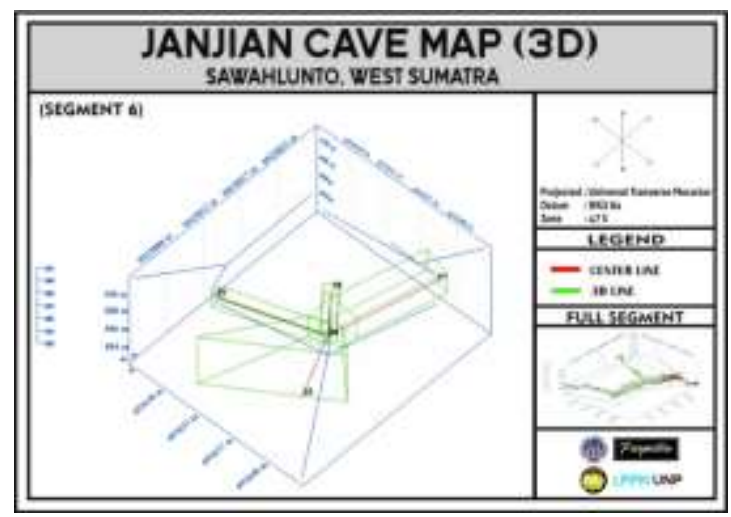

Gambar 11. Peta gua janjian segmen 6

Setelah pengumpulan data, gambar 12 menunjukkan speleothem gua yang harus dilindungi. 


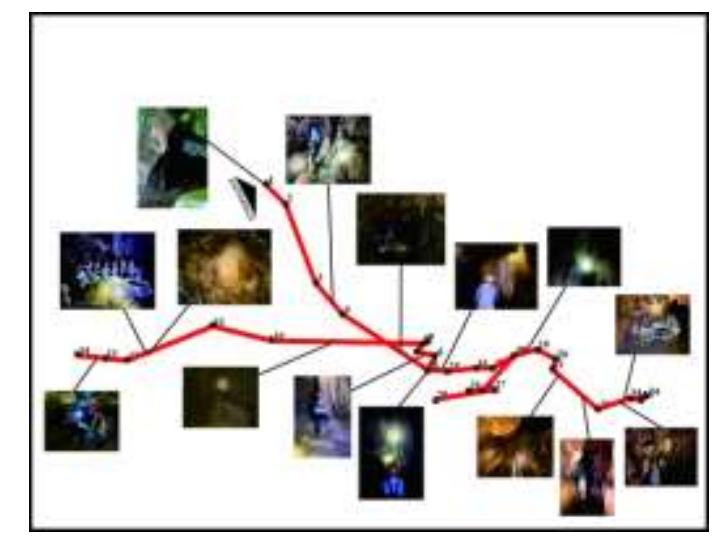

Gambar 12. Distribusi gua speleothems

\section{KESIMPULAN}

Hasil penelitian Gua Janjian memperoleh informasi tentang keberadaan benda-benda yang harus dilindungi, seperti ornamen gua berupa stalaktit dan stalagmit, selain gua. Speleothems, ada juga biota seperti kelelawar, burung dan artropoda. Dengan adanya obyekobyek yang harus dilindungi, hasil pemetaan gua ini merupakan langkah awal bagi pelestarian lingkungan, khususnya pelestarian kart di masa depan.

\section{DAFTAR PUSTAKA}

Agniy, RF dkk. (2019). Karakterisasi rongga Gua Anjani di Kawasan Karst Jonggrangan, Purworejo, Jawa Tengah, Indonesia. Konferensi IOP Seri: Ilmu Bumi dan Lingkungan 256.

Alt, L \& Moura, V (2013), 'Penggunaan Pemetaan Dampak untuk Perencanaan Infrastruktur di Gua Wisata - Studi Kasus: Gua Maquine, Simposium Pengelolaan Gua dan Karst Nasional Brasil, Carlsbad, New Mexico, 4-8 November 2013.

Amalia, W., Samekto, A., \& Prihatin, ES (2016). Perlindungan hukum kawasan karst terhadap kegiatan penambangan dalam kaitannya dengan pengelolaan lingkungan (studi kasus penambangan batu kapur di kawasan karst Gombong Selatan, Kebumen, Jawa Tengah). Reformasi Hukum, 12(1), 132-144

Drew D dan Hotzl H (1999) Hidrogeologi Karst dan Aktivitas Manusia. (Rotterdam: AA Balkema).

Ford, \& Williams. (2013). Hidrogeologi dan Geomorfologi Karst. John Wiley \& Sons Ltd, Atrium, Gerbang Selatan, Chichester, West Sussex PO19 8SQ, Inggris.

Matius, P., Rahmadi, D., Setiawan, D., \& Mt, D. (2016). Pedoman Praktis Survei Terpadu Kawasan Karst.

Nurkholis A Adji TN Haryono E Cahyadi A dan Agniy RF 2017 Variasi spasial dan temporal karakteristik aliran terhadap karakterisasi akuifer Sistem Karst Pindul, Kabupaten Gunungkidul Proc. Konferensi Tahunan ke-2 Perhimpunan Ahli Air Tanah (PITPAAI), 13-15 September 2017, Yogyakarta.

Sarwanto, Doso dan Hadi, Caribu. (2015). Keanekaragaman dan produktivitas hijauan pakan ternak asli bekas tambang batugamping di pegunungan karst Gombong Selatan, Jawa 
Tengah Indonesia . Produksi hewan, 17 (2), 69-75.

Trudgill S (1985) Geomorfologi Batugamping (Hongkong: Longma).

Uca, U., \& Angriani, R. (2018). Pemetaan Kawasan Karst Gua Kalibbong Aloa Pangkep. Sainsmat: Jurnal Ilmiah Ilmu Pengetahuan Alam, 7(2), 92-101. Alam, 7(2), 92-101. 